\title{
Near-normal aerobic capacity in long- term survivors after lung transplantation
}

\author{
Berta Saez-Gimenez ${ }^{1,10}$, Miriam Barrecheguren ${ }^{1,10}$, Maria Antònia Ramon (1) ${ }^{1,2}$, \\ Alba Gomez-Garrido ${ }^{3}$, Carlos Bravo ${ }^{1,2}$, Víctor Monforte ${ }^{1,2}$, \\ Manuel López-Meseguer ${ }^{1}$, Cristina Berastegui ${ }^{1}$, Eva Revilla (101, \\ Christian Romero ${ }^{1}$, Rosalía Laporta ${ }^{4}$, Sonia Fernández-Rozas ${ }^{5}$, \\ Javier Redel-Montero ${ }^{6}$, Amparo Solé ${ }^{7}$, Mercedes de la Torre ${ }^{8}$, Luis Puente (1) 9 , \\ Antonio Roman ${ }^{1,2}$, Susana Gómez-Ollés ${ }^{1,2,11}$ and Iñigo Ojanguren (1) 1,2,11
}

Affiliations: 'Servicio de Neumología, Hospital Universitari Vall d'Hebron, Departamento de Medicina, Universidad Autónoma de Barcelona (UAB), Barcelona, Spain. ${ }^{2}$ CIBER Enfermedades Respiratorias (CIBERES), Barcelona, Spain. ${ }^{3}$ Servicio de Rehabilitación, Hospital Universitario Vall d'Hebron, UAB, Barcelona, Spain. ${ }^{4}$ Servicio de Neumología, Hospital Universitario Puerta Hierro, Universidad Autónoma de Madrid, Madrid, Spain. ${ }^{5}$ Servicio de Neumología, Hospital Marqués de Valdecilla, Santander, Spain. ${ }^{6}$ Servicio de Neumología, Hospital Reina Sofía, Córdoba, Spain. ${ }^{7}$ Servicio de Neumología, Hospital Politécnico Universitario La Fe, Universidad de Valencia, Valencia, Spain. ${ }^{8}$ Servicio de Cirugía Torácica y Trasplante Pulmonar, Hospital Universitario A Coruña, A Coruña, Spain. ${ }^{9}$ Servicio de Neumología, Hospital General Universitario Gregorio Marañón, Madrid, Spain. ${ }^{10}$ These authors contributed equally. ${ }^{11}$ These authors contributed equally.

Correspondence: Berta Saez-Gimenez, Servei de Pneumologia, Hospital Universitari Vall d'Hebron, Passeig Vall d'Hebron, 119-129, 08035 Barcelona, Spain. E-mail: bsaezavhebron.net

ABSTRACT The clinical course of lung transplantation (LT) is diverse: some patients present chronic lung allograft dysfunction (CLAD) and progressive decline in pulmonary function, but others maintain normal spirometric values and active lives.

Objectives: The aim of this study was to elucidate whether long-term LT survivors with normal spirometry achieve normal exercise capacity, and to identify predictive factors of exercise capacity.

Methods: This was a cross-sectional multicentre study, where bilateral LT recipients who survived at least 10 years after LT, with normal spirometry, no diagnosis of CLAD and modified Medical Research Council dyspnoea degree $\leqslant 2$ underwent cardiopulmonary exercise testing (CPET).

Results: 28 LT recipients were included with a mean \pm SD age of $48.7 \pm 13.6$ years. Oxygen uptake $\left(V^{\prime}{ }_{\mathrm{O}_{2}}\right)$ had a mean \pm SD value of $21.49 \pm 6.68 \mathrm{~mL} \cdot \mathrm{kg}^{-1} \cdot \mathrm{min}^{-1}(75.24 \pm 15.6 \%)$ and the anaerobic threshold was reached at $48.6 \pm 10.1 \%$ of the $V^{\prime}{ }_{\mathrm{O}_{2}}$ max predicted. The mean \pm SD heart rate reserve at peak exercise was $17.56 \pm 13.6 \%$. The oxygen pulse increased during exercise and was within normal values at $90.5 \pm 19.4 \%$. The respiratory exchange ratio exceeded 1.19 at maximum exercise. The median $\left(25-75^{\text {th }}\right.$ percentile) EuroQol-5D score was 1 (0.95-1), indicating a good quality of life. The median $\left(25-75^{\text {th }}\right.$ percentile) International Physical Activity Questionnaire score was 5497 (4007-9832) MET-min.week ${ }^{-1}$ with 89\% of patients reporting more than $1500 \mathrm{MET}-\mathrm{min} \cdot \mathrm{week}^{-1}$. In the multivariate regression models, age, sex and diffusing capacity of the lung for carbon monoxide remained significantly associated with $V_{\mathrm{O}_{2}}^{\prime} \max \left(\mathrm{mL} \cdot \mathrm{kg}^{-1} \cdot \mathrm{min}^{-1}\right)$; haemoglobin and forced expiratory volume in $1 \mathrm{~s}$ were significantly associated with maximum work rate (watts), after adjusting for confounders.

Conclusion: We report for the first time near-normal peak $V_{\mathrm{O}_{2}}^{\prime}$ values during CPET and normal exercise capacity in long-term LT recipients without CLAD.

@ERSpublications

This is a multicentre study reporting, for the first time, near-normal peak $V_{\mathrm{O} 2}^{\prime}$ values during cardiopulmonary exercise testing and normal exercise capacity in long-term lung transplant recipients without CLAD https://bit.ly/35ftce3

Cite this article as: Saez-Gimenez B, Barrecheguren M, Ramon MA, et al. Near-normal aerobic capacity in long-term survivors after lung transplantation. ERJ Open Res 2021; 7: 00381-2020 [https://doi.org/10.1183/23120541.00381-2020]. 


\section{Introduction}

Lung transplantation (LT) is an established treatment for end-stage respiratory diseases, which improves patient's health-related quality of life (HRQoL), especially in the physical functioning domains [1]. Despite improvements in respiratory symptoms and pulmonary function, reports from the early 1990s showed a reduction in peak oxygen uptake $\left(V^{\prime}{ }_{\mathrm{O} 2}\right)$ ranging between $44 \%$ and $59 \%$ in single LT, and between $40 \%$ and $50 \%$ in bilateral LT [2-6] with little or no improvement after 2 years of follow-up.

Transferring the results of these studies to the clinical field is difficult because of their small sample sizes, evaluation of specific LT type, and the different timing of exercise testing and lung function. All the authors that have previously addressed this topic share the view that LT recipients, either for intrinsic or extrinsic reasons, do not reach normal oxygen consumption values. However, in our clinical experience, while some patients develop chronic lung graft dysfunction and a progressive decline in lung function, others attain normal spirometric values and are able to carry out considerable activities despite presenting good exercise capacity [2-6]. The most common causes invoked to explain low exercise capacity, in spite of the striking recovery of lung function after LT, are anaemia, cardiac and peripheral vascular factors, impaired oxidative capacity of peripheral skeletal muscle, lower limb skeletal muscle dysfunction, muscle weakness and sarcopenia $[2,7,8]$. The literature supporting these mechanisms is scarce and severe muscle deconditioning (which could be reverted with time) is a very plausible additional explanation. To explore this possibility, studies analysing exercise capacity and other exercise variables in the long term are needed. As far as we know, such studies are lacking and as a result, obtaining definite conclusions regarding the causes of exercise limitation in LT recipients remains a challenging task. Nevertheless, we hypothesise that LT recipients with normal lung function and generally good health status could preserve near-normal $V^{\prime}$ 22 values.

We therefore analysed exercise capacity in long-term survivors after bilateral LT with normal lung function tests. Our aims were: 1) to establish whether these patients could achieve normal exercise capacity, and 2) to identify predictive factors of exercise capacity in this LT population.

\section{Methods}

Study design

A prospective cross-sectional study was performed in LT recipients recruited from six different LT referral centres from all over Spain, between 2015 and 2016. The study was approved by the Institutional Ethics Board (Vall d'Hebron Hospital, Barcelona, ID of approval: PR(AG)64/2015), and all the participants provided signed informed consent.

\section{Subjects}

Inclusion criteria were: 1) bilateral LT conducted at least 10 years prior to the inclusion date; 2) normal spirometry (forced vital capacity (FVC) and forced expiratory volume in $1 \mathrm{~s}\left(\mathrm{FEV}_{1}\right)>80 \%$ and $\mathrm{FEV}_{1} / \mathrm{FVC}$ ratio >0.7); 3) no diagnosis of chronic lung allograft dysfunction (CLAD); 4) ability to complete cardiopulmonary exercise testing (CPET); and 5) dyspnoea degree 2 or lower on the modified Medical Research Council score (mMRC).

Demographic and clinical data such as sex, age, smoking history, date of LT and current treatment were recorded or obtained from medical records. Physical activity was measured with the long form of the International Physical Activity Questionnaire (IPAQ), which calculates the total energy expenditure per week (METs-min·week ${ }^{-1}$ ) from the time (in minutes) spent walking and performing moderate-intensity and vigorous-intensity physical activity in four different domains (leisure time, domestic, work-related and transport-related physical activity) [9]. HRQoL was assessed through the "EuroQol-5D" test [10], which comprises five questions on mobility, self-care, pain, usual activities and psychological state.

All the tests were performed in the same centre (Hospital Universitari Vall d'Hebron), so the patients were required to travel, if necessary.

\section{Pulmonary function testing}

All patients underwent forced spirometry, static lung volume study by plethysmography, and single-breath lung diffusing capacity for carbon monoxide $\left(D_{\mathrm{LCO}}\right)$ using the single breath-hold method (MasterLab, Vyasisr, Hochburg Germany). These studies were performed following the recommendations of the European [11] and Spanish Respiratory Societies [12].

\section{Cardiopulmonary exercise testing}

CPET was performed on a cycle ergometer using a breath-by-breath system (MEDGRAPHICS CPX, St Paul, MN, USA). The speed of the ramp protocol was determined according to the maximum voluntary ventilation $(\mathrm{MVV})$ : for $\mathrm{MVV}<40 \mathrm{~L} \cdot \mathrm{min}^{-1}$ at $10 \mathrm{~W} \cdot \mathrm{min}^{-1}$ and for $\mathrm{MVV}>40 \mathrm{~L} \cdot \mathrm{min}^{-1}$ at $15 \mathrm{~W} \cdot \mathrm{min}^{-1}[13]$, 
with this adjustment in our experience the test usually lasted between 10 and 15 min. After 3 min resting and $3 \mathrm{~min}$ of unloaded pedalling, the workload was progressively increased in order to obtain a test lasting 8-12 min. Oxygen saturation and pulse rate was continuously monitored along the test. Breath-by-breath the following features were recorded: $V_{\mathrm{O}_{2}}^{\prime}$, carbon dioxide output $\left(V_{\mathrm{CO}_{2}}^{\prime}\right)$, minute ventilation $\left(V_{\mathrm{E}}^{\prime}\right)$, pulse rate (PR), arterial blood pressure, dyspnoea, and leg fatigue (Borg). Subjects were asked to maintain a pedalling cadence between 50 and 60 revolutions per min for the duration of the test. If cadence declined and fell below 40 revolutions per min for longer than $5 \mathrm{~s}$, the test was terminated [13].

\section{Free-fat body mass measurement}

Tissue composition analysis was performed by electrical bioimpedance equipment $50 \mathrm{~Hz}$ (BIA 101, Akern Srl; Florence, Italy). Single-frequency bioelectrical impedance analysis was carried out with an impedance plethysmograph that emitted $400 \mu \mathrm{A}$ and $50 \mathrm{kHz}$ alternating sinusoidal current and was connected to surface electrodes (standard, tetrapolar placement on the right hand and foot) following the method reported elsewhere [14].

\section{Statistics}

The results are expressed as absolute frequencies and percentages for qualitative variables, as mean $\pm \mathrm{SD}$ for quantitative variables with a normal distribution, and as the median and interquartile range (IQR) for quantitative variables with a non-normal distribution. The relationship between sociodemographic, clinical and functional variables and exercise capacity was tested by means of a Chi-squared test, Fisher's exact test, t-test, Mann-Whitney U-test and Spearman's correlation coefficient as appropriate. For variables

\section{TABLE 1 Clinical characteristics of lung transplant (LT) recipients}

\begin{tabular}{|c|c|}
\hline Subjects $n$ & 29 \\
\hline Age years & $48.7 \pm 13.6$ \\
\hline Male sex $n(\%)$ & $14(48)$ \\
\hline Age at the time of LT years & $34.7 \pm 14.0$ \\
\hline Years since LT & $14.0 \pm 3.1$ \\
\hline \multicolumn{2}{|l|}{ Diagnosis } \\
\hline COPD & $3 \pm 10.3$ \\
\hline ILD & $4 \pm 13.7$ \\
\hline CF & $14 \pm 48.3$ \\
\hline Bronchiectasis & $1 \pm 3.5$ \\
\hline $\mathrm{PH}$ & $1 \pm 3.5$ \\
\hline Other & $6 \pm 20.7$ \\
\hline BMI $\mathrm{kg} \cdot \mathrm{m}^{-2}$ & $21.6 \pm 5.6$ \\
\hline FFMI $\mathrm{kg} \cdot \mathrm{m}^{-2}$ & $16.6 \pm 4.1$ \\
\hline Haemoglobin $\mathrm{g} \cdot \mathrm{dL}^{-1}$ & $13.3 \pm 1.5$ \\
\hline Arterial hypertension $\mathrm{n}(\%)$ & $15(51.7)$ \\
\hline Diabetes mellitus n (\%) & $6(20.7)$ \\
\hline Dyslipidaemia n (\%) & 11 (37.9) \\
\hline \multicolumn{2}{|l|}{ Smoking history $\mathrm{n}(\%)$} \\
\hline Never smoked & $21(72.4)$ \\
\hline Former smoker & $8(27.6)$ \\
\hline Packs per year & $29.7 \pm 23.4$ \\
\hline \multicolumn{2}{|l|}{ Lung function } \\
\hline FVC L & $3.9 \pm 0.92$ \\
\hline FVC $\%$ predicted & $92.6 \pm 15.7$ \\
\hline $\mathrm{FEV}_{1} \mathrm{~L}$ & $3.1 \pm 0.7$ \\
\hline $\mathrm{FEV}_{1} \%$ predicted & $97.9 \pm 14.5$ \\
\hline$D_{\mathrm{LCO}}\left(\mathrm{mL} \cdot \mathrm{mmHg}^{-1} \cdot \mathrm{min}^{-1}\right)$ median (IQR) & $77.1(70-83.3)$ \\
\hline TLC $\%$ predicted & $96.1 \pm 18.3$ \\
\hline RV \% predicted & $81.0 \pm 8.5$ \\
\hline Oral corticosteroids $\mathrm{n}(\%)$ & $28(96.6)$ \\
\hline Oral corticosteroids dosage mg & $3.9 \pm 1.6$ \\
\hline \multicolumn{2}{|c|}{$\begin{array}{l}\text { Data are presented as mean } \pm \mathrm{SD} \text {, unless otherwise stated. Some variables have missing values: eight in } \\
\text { FFMI, one in packs per year and one in corticosteroid dosage. ILD: interstitial lung disease; CF: cystic } \\
\text { fibrosis; } \mathrm{PH} \text { : pulmonary hypertension; BMI: body mass index; FFMI: fat-free mass index; FVC: forced vital } \\
\text { capacity; } F E V_{1} \text { : forced expiratory volume in } 1 \mathrm{~s} ; D_{\mathrm{Lco}} \text { : diffusing capacity of the lung for carbon monoxide; } \\
\text { IQR: interquartile range; TLC: total lung capacity; RV: residual volume. }\end{array}$} \\
\hline
\end{tabular}


significantly related to exercise performance, a stepwise multiple linear regression with a backward elimination (entry threshold, $\mathrm{p}<0.05$; removal threshold, $\mathrm{p}>0.10$ ) was performed using $V^{\prime} \mathrm{O} 2$ peak and work rate (WR) peak as dependent variables. To avoid collinearity, we used the variable with the highest correlation ( $r$ ) with exercise capacity in bivariate regression analyses. Analyses were adjusted for age and sex and goodness of fit was assessed by means of normality of residuals, heteroscedasticity, linearity, collinearity and identification of influential data. Limits of significance were set at $\mathrm{p}<0.05$. Data analysis was conducted using Stata 12.1 (StataCorp, College Station, TX, USA).

\section{Results}

\section{Subject characteristics}

28 consecutive patients met the inclusion criteria and agreed to participate in this study. Six patients declined to take part in the study due to travelling or competing commitments. Subject demographics are shown in table 1 . Mean \pm SD age was $48.7 \pm 13.6$ years, and there was an equal distribution between men and women. The majority of patients (48.3\%) had cystic fibrosis (CF) as the underlying disease requiring LT, normal body mass index and normal lean mass. Cardiovascular risk factors were seen in $51.7 \%$ of patients.

Regarding immunosuppressive treatment, $79 \%$ of patients were receiving tacrolimus (mean blood level $8.6 \mathrm{ng} \cdot \mathrm{mL}^{-1}$ ), $20 \%$ cyclosporine (mean blood level $181.2 \mathrm{ng} \cdot \mathrm{mL}^{-1}$ ), $66 \%$ mycophenolate (mean dosage $1087 \mathrm{mg} \cdot \mathrm{day}^{-1}$ ) and $28 \%$ azathioprine (mean dosage $62.5 \mathrm{mg} \cdot \mathrm{day}^{-1}$ ). 28 patients out of 29 were on oral steroids at a mean \pm SD dose of $3.89 \pm 1.57 \mathrm{mg}$.

\section{Metabolic response to exercise}

$V^{\prime} \mathrm{O} 2$ peak, WR, heart rate (HR), heart rate reserve (HRR), $\mathrm{O}_{2}$ pulse, and respiratory exchange ratio (RER) during exercise are shown in table $2 . V^{\prime}{ }_{\mathrm{O} 2}$ had a mean value of $21.49 \pm 6.68 \mathrm{~mL} \cdot \mathrm{kg}^{-1} \cdot \mathrm{min}^{-1}(75.24 \pm 15.6 \%$ of predicted value) and the anaerobic threshold was reached at $48.6 \pm 10.1 \%$ of predicted value. There were no differences between males and females or CF and non-CF patients (data not shown).

\section{Circulatory response to exercise}

The mean \pm SD HRR at peak exercise was $17.56 \pm 13.6 \%$. The $\mathrm{O}_{2}$ pulse increased during exercise in all patients and was within normal values, at $90.5 \pm 19.4 \%$. The RER exceeded 1.19 in all patients at maximum exercise. The mean \pm SD peak venous blood lactate level was $7.35 \pm 1.89 \mathrm{mmol} \cdot \mathrm{L}^{-1}$ (table 2 ).

\section{Ventilatory and gas exchange response to exercise}

Table 2 shows the ventilatory and gas exchange variables during exercise. The median (IQR) peak $V_{E}^{\prime}$ was 54 (48-67.1) L.min ${ }^{-1}$. Maximum $V_{\mathrm{E}}^{\prime}$ averaged 52\% (48-57) of the calculated MVV. The median (IQR)

\section{TABLE 2 Exercise capacity, physical activity and quality of life of lung transplant (LT) recipients}

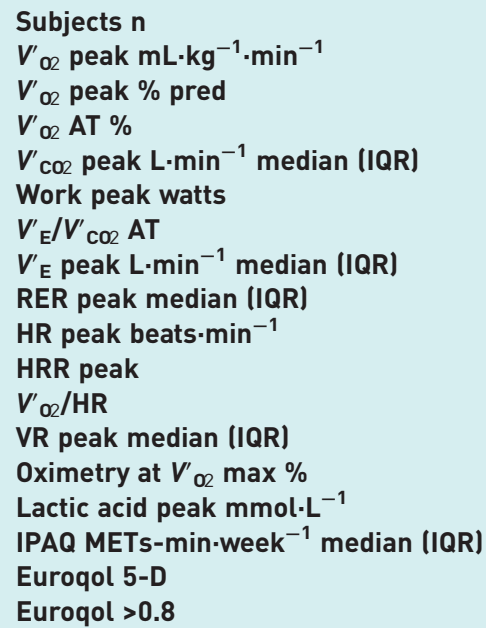

Data are presented as mean \pm SD, unless otherwise stated. $V^{\prime}{ }_{02}$ : oxygen uptake; $V^{\prime}{ }_{\text {CO2 }}$ : carbon dioxide output; IQR: interquartile range; AT: aerobic threshold; $V_{E}^{\prime}$ : minute ventilation; RER: respiratory exchange ratio; HR: heart rate; HRR: heart rate reserve; VR: ventilator reserve; IPAQ: International Physical Activity Questionnaire. 
value for $V^{\prime}{ }^{\prime} / V^{\prime} \mathrm{CO}_{2}$ at ventilatory threshold was 32 (31-35). The oxygen saturation was normal at peak exercise in all individuals.

HRQoL and physical activity

The median $\left(25-75^{\text {th }}\right.$ percentile) EuroQol- 5D score was $1(0.95-1)$, showing a good quality of life in all subjects.

The median (25-75 ${ }^{\text {th }}$ percentile) IPAQ score was 5497 (4007-9832) MET-min.week ${ }^{-1}$, with the majority of patients $(89 \%)$ reporting $>1500 \mathrm{MET}$-min.week ${ }^{-1}$.

\section{Correlations and adjusted analysis to predict peak $\mathrm{V}^{\prime}{ }_{02}$ and peak WR}

There was a positive correlation between peak $V_{\mathrm{O}_{2}}^{\prime}\left(\mathrm{mL} \cdot \mathrm{kg}^{-1} \cdot \mathrm{min}^{-1}\right)$ and haemoglobin $(\mathrm{Hb})$ values $(\mathrm{r}=0.555 ; \mathrm{p}=0.002)$, basal FVC (L) $(\mathrm{r}=0.571 ; \mathrm{p}=0.001), \mathrm{FEV}_{1}(\mathrm{~L})(\mathrm{r}=0.675 ; \mathrm{p}<0.001), D_{\mathrm{LCO}}$ (\% pred) $(\mathrm{r}=0.656 ; \mathrm{p}<0.001)$ and a negative correlation between $V_{\mathrm{O}_{2}}^{\prime}\left(\mathrm{mL} \cdot \mathrm{kg}^{-1} \cdot \mathrm{min}^{-1}\right)$ and age (years) $(\mathrm{r}=-0.491$; $\mathrm{p}=0.007)$. There was a positive correlation between $V_{\mathrm{O}_{2}}^{\prime}$ (\% pred) and $\mathrm{FVC}(\%$ pred $)(\mathrm{r}=0.421 ; \mathrm{p}=0.023)$, $\mathrm{FEV}_{1}$ (\% pred) $(\mathrm{r}=0.414 ; \mathrm{p}=0.026)$, total lung capacity (\% pred) $(\mathrm{r}=0.427 ; \mathrm{p}=0.021)$ and $D_{\mathrm{LCO}}(\%$ pred $)$ $(\mathrm{r}=0.569 ; \mathrm{p}=0.002)$. Peak WR correlated positively with $\mathrm{Hb}\left(\mathrm{g} \cdot \mathrm{dL}^{-1}\right)$ and $\mathrm{FEV}_{1}(\mathrm{~L})(\mathrm{r}=0.525 ; \mathrm{p}=0.004$ and $\mathrm{r}=0.616 ; \mathrm{p}<0.001$, respectively) and negatively with age (years) $(\mathrm{r}=-0.469 ; \mathrm{p}=0.010)$ (figures 1 and 2).

In the multivariate regression models (table 3 ), only age, sex and $D_{\mathrm{LCO}}$ remained significantly associated with peak $V_{\mathrm{O} 2}^{\prime}\left(\mathrm{mL} \cdot \mathrm{kg}^{-1} \cdot \mathrm{min}^{-1}\right)$; and $\mathrm{Hb}$ and $\mathrm{FEV}_{1}$ with peak WR (watts), after adjusting for confounders. Linear regression goodness of fit tests did not reveal any abnormality.

The adjusted predicted peak $V_{\mathrm{O}_{2}}^{\prime}$ value (and 95\% confidence interval) was plotted against $D_{\text {LCO }}$ (figure 3 ) and shows that the higher the $D_{\text {LCO }}$ value, the greater the exercise capacity, in a linear dose-response manner. Likewise, figure 4 depicts the adjusted linear dose-response WR peak (watts) predicted values (and 95\% confidence intervals) according to $\mathrm{Hb}\left(\mathrm{g} \cdot \mathrm{dL}^{-1}\right)$.

\section{Discussion}

In this study long-term LT survivors with preserved lung function presented a mean peak $V^{\prime} \mathrm{O}_{2}$ value of $75.24 \%$ of their maximum predicted value, that is, near-normal exercise capacity. The multivariate
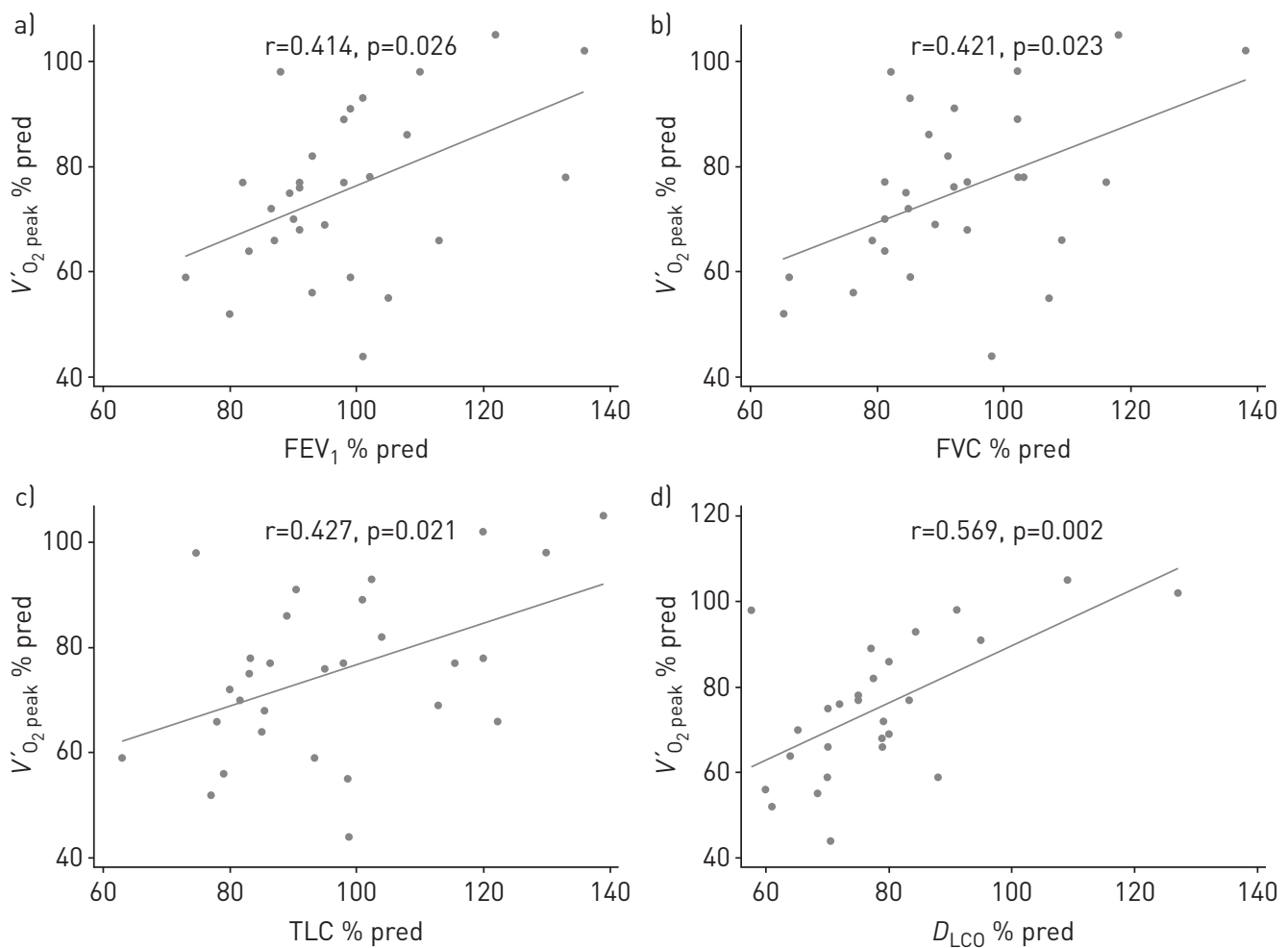

FIGURE 1 Correlations between peak oxygen uptake ( $V^{\prime}{ }_{2}$ peak) (\% predicted) and a) forced expiratory volume in $1 \mathrm{~s}\left(\mathrm{FEV}_{1}\right)(\%$ predicted), b) forced vital capacity (FVC) (\% predicted), c) total lung capacity (TLC) (\% predicted) and d) diffusing capacity of the lungs for carbon monoxide $\left(D_{\mathrm{LCO}}\right)(\%$ predicted). 

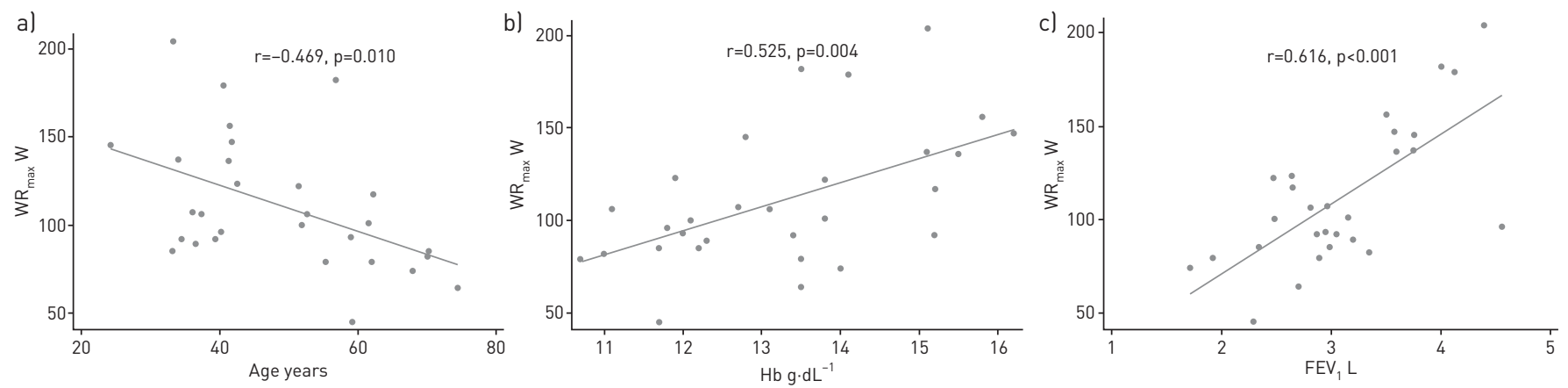

FIGURE 2 Correlations between maximum work rate $\left(\mathrm{WR}_{\max }\right)$ (watts) and a) age, b) haemoglobin ( $\mathrm{Hb}$ ) and $\mathrm{c}$ ) forced expiratory volume in $1 \mathrm{~s}\left(\mathrm{FEV} \mathrm{V}_{1}\right)$ (L).

regression model revealed significant associations between age, sex and $D_{\mathrm{LCO}}$ and peak $V^{\prime} \mathrm{O}_{2}$ $\left(\mathrm{mL} \cdot \mathrm{kg}^{-1} \cdot \mathrm{min}^{-1}\right)$, and between $\mathrm{Hb}$ and $\mathrm{FEV}_{1}$ and peak WR (watts), after adjusting for confounders. The median $\left(25-75^{\text {th }}\right.$ percentile) EuroQol-5D score was $1(0.95-1)$, indicating a good quality of life in all subjects.

During the 1990s, several authors reported small samples of LT patients with peak $V_{\mathrm{O} 2}^{\prime}$ values ranging between $38 \%$ and $60 \%$ of the maximum predicted value $[2-5,15]$. Later, BARTELs et al. [7] described a sample of 78 bilateral LT recipients recruited between 2001 and 2009 who presented a mean peak $V^{\prime} \mathrm{O}_{2}$ value of $52 \%$ of the maximum predicted value 30 months after LT. Recently, ULVESTAD et al. [16] reported a peak $V_{\mathrm{O}_{2}}^{\prime}$ of $57 \%$ and $70 \%$ for men and women, respectively, in a sample of 54 patients in a period ranging from 6 to 60 months after bilateral LT. In the present study the mean peak $V^{\prime} \mathrm{O}_{2}$ value was $75.24 \%$ of the maximum predicted value, indicating a much higher exercise capacity than in previous studies. These findings need to be framed in the context of a highly active subpopulation, although it should not be undermined that this study proves that even in selected LT recipients, near-normal peak $V_{\mathrm{O}_{2}}^{\prime}$ values are achievable after undergoing LT.

Like BARTELs et al. [7], we observed no cardiac or ventilatory limitations. Although in both studies all patients presented normal $\mathrm{FEV}_{1}$, in the study by BARTELS et al., the mean $D_{\mathrm{LCO}}$ value was $57 \%$ while ours was $77.5 \%$. Similarly, Mryoshi et al. [3] described a mean $V^{\prime} \mathrm{O}_{2}$ peak value of $48.5 \%$ in six double-LT patients undergoing CPET in a range between 6 and 48.5 months after surgery. While the six patients presented normal $\mathrm{FEV}_{1}$ and $D_{\mathrm{LCO}}$ values after LT, they had a mean $\mathrm{Hb}$ value of $10.8 \mathrm{mg} \cdot \mathrm{dL}^{-1}$; therefore, the authors suggested anaemia as the main cause for exercise limitation. Schwaiblmair et al. [4] also reported peripheral deficiencies in oxygen transport as the major cause of exercise limitation in 32 bilateral LT recipients undergoing CPET within 3 months of LT. These patients presented a mean peak $V_{\mathrm{O}_{2}}^{\prime}$ of $40.2 \%$ of the predicted value along with mean $\mathrm{FEV}_{1}$ and $D_{\mathrm{LCO}}$ values of $66.6 \%$ and $69.4 \%$, respectively and also a mean $\mathrm{Hb}$ of $10.9 \mathrm{~g} \cdot \mathrm{dL}^{-1}$. The positive correlation between the peak $V_{\mathrm{O}_{2}}^{\prime}$ value $\left(\mathrm{mL} \cdot \mathrm{kg}^{-1} \cdot \mathrm{min}^{-1}\right)$ and $\mathrm{Hb}$ and the inverse correlation between peak $V^{\prime} \mathrm{O}_{2}$ and age found in the present study suggests that these factors are crucial and determine exercise capacity in LT recipients. Indeed, in our study the stepwise multiple regression analysis for peak workload revealed anaemia as an independent predictor. Medication

TABLE 3 Results of stepwise multiple regression analysis for maximal oxygen uptake $\left(\mathrm{V}^{\prime} \mathrm{O}_{2} \mathrm{max}\right)$ and maximum workload

\begin{tabular}{|c|c|c|c|c|}
\hline & \multicolumn{2}{|c|}{$V_{\text {O2max }}^{\prime} \mathrm{mL} \cdot \mathrm{kg}^{-1} \cdot \mathrm{min}^{-1}$} & \multicolumn{2}{|c|}{ Maximum workload watts } \\
\hline & Coefficient $(95 \% \mathrm{CI})$ & p-value & Coefficient $(95 \% \mathrm{CI})$ & p-value \\
\hline Age years & $-0.249(-0.37--0.13)$ & $<0.001$ & $-0.24(-1.17-0.69)$ & 0.599 \\
\hline Male sex & $5.35(2.19-8.51)$ & 0.002 & $4.72(-34.75-25.30)$ & 0.748 \\
\hline Haemoglobin $\mathrm{g} \cdot \mathrm{dL}^{-1}$ & & & $9.62(2.21-17.02)$ & 0.013 \\
\hline $\mathrm{FEV}_{1} \mathrm{~L}$ & & & $31.53(8.88-54.17)$ & 0.008 \\
\hline$D_{\text {Lco }} \%$ predicted & $0.26(0.15-0.36)$ & $<0.001$ & & \\
\hline Constant & $18.87(16.80-20.95)$ & $<0.001$ & & \\
\hline Adjusted $\mathbf{R}^{2}$ & 0.685 & & 0.580 & \\
\hline
\end{tabular}


FIGURE 3 Adjusted predicted maximal oxygen uptake $\left(V^{\prime} \mathrm{O}_{2} \max \right)$ values land $95 \%$ confidence intervall against diffusing capacity of the lungs for carbon monoxide $\left(D_{\mathrm{LCO}}\right)$.

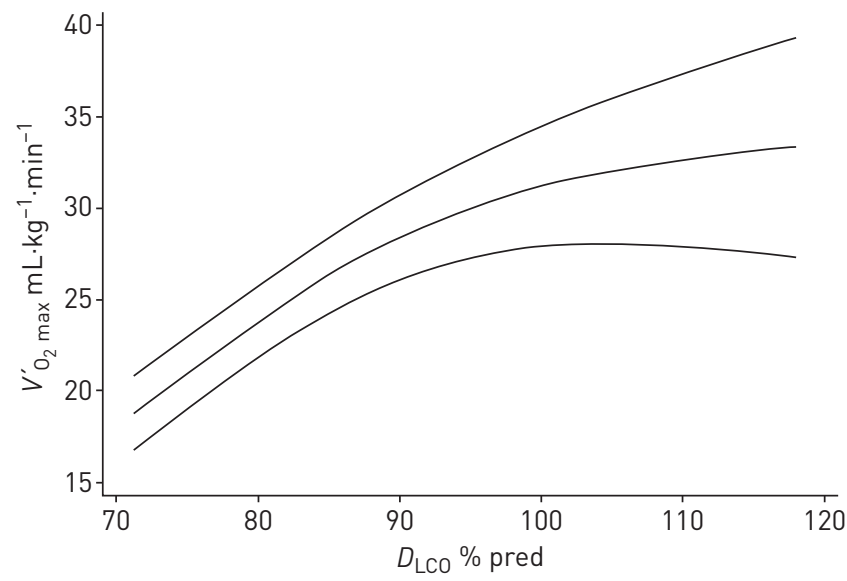

effects, immune-mediated factors and various forms of haemolysis may all contribute to developing anaemia, which can affect oxygen transport and tissue extraction even in mild cases [16].

In agreement with previous findings, we recorded a positive correlation between peak $V_{\mathrm{O}_{2}}^{\prime}\left(\mathrm{mg} \cdot \mathrm{kg}^{-1} \cdot \mathrm{min}^{-1}\right.$ and $\%$, respectively) and pulmonary function values. The stepwise multiple regression analysis for peak $V^{\prime} \mathrm{O}_{2}\left(\mathrm{~mL} \cdot \mathrm{kg}^{-1} \cdot \mathrm{min}^{-1}\right)$ showed $D_{\mathrm{LCO}}(\%$ predicted) as an independent predictor. In a process such as bilateral LT in which histological alterations reduce the area of gas exchange, it is plausible to think that the determination most able to predict $V^{\prime} \mathrm{O}_{2}$ max is $D_{\mathrm{LCO}}$. In fact, in other processes such as idiopathic pulmonary fibrosis [17] or COPD [18], which like bilateral LT, show falls in these parameters and hypoxaemia and respiratory insufficiency in advanced stages, there is a growing consensus that $D_{\text {LCO }}$ should be added not only for patient diagnosis and management but also for the evaluation of the response to new drugs in clinical trials. In this regard, and also in relation to $D_{\mathrm{LCO}}$, the stepwise multiple regression analysis for peak WR (watts) identified $\mathrm{Hb}\left(\mathrm{mg} \cdot \mathrm{mL}^{-1}\right)$ as an independent predictor of peak $V^{\prime} \mathrm{O}_{2}$. Although these results suggest that small changes in $D_{\mathrm{LCO}}$ might significantly impact $\% V_{\mathrm{O}_{2}}^{\prime} \max$ values, they should be cautiously interpreted and confirmation in other studies is needed.

There is no standard inventory for formally evaluating HRQoL in transplant medicine. However, several authors have reported significant improvement in almost all HRQoL domains in the first 3 years after transplant [19-22]. Vermuelen et al. [23] described HRQoL comparable with that in the general population after LT although they observed a fall over time in relation to the rising incidence of bronchiolitis obliterans syndrome and comorbid conditions. However, there are few studies analysing HRQoL in long-term LT survivors. Other authors [23-25] reported significantly reduced HRQoL in the main domains in LT recipients surviving periods ranging from 5 to 10 years. The median $\left(25-75^{\text {th }}\right.$ percentile) EuroQol-5D score in the present study was $1(0.95-1)$, indicating a good quality of life in all subjects. These findings contrast with those described by previous authors, although the differences are most likely to be related to the study entry criteria.

FIGURE 4 Adjusted predicted maximum work rate $\left(\mathrm{WR}_{\max }\right)$ values land 95\% confidence interval) against haemoglobin $(\mathrm{Hb})$.

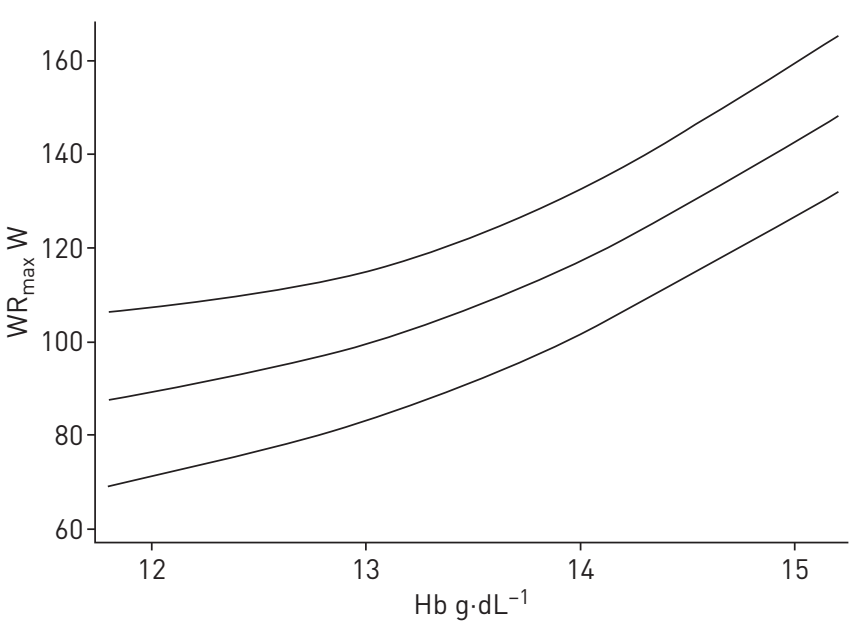


Regarding physical activity, notable improvements with regard to pre-transplant symptoms have been reported by several studies [26-28]. Over time, however, many LT recipients reported new symptoms related to limb muscle dysfunction (muscle atrophy, muscle weakness and changes in muscle composition and metabolism) and other comorbidities. The LT recipients in our study presented a median $\left(25-75^{\text {th }}\right.$ percentile) IPAQ score of 5497 (4007-9832) MET-min.week ${ }^{-1}$, and most (89\%) reported more than $1500 \mathrm{MET}-\mathrm{min} \cdot \mathrm{week}^{-1}$. All reported a high amount of activity in the five domains analysed. Again, these findings may be related to the particular characteristics of our study population. Without doubt the high amount of daily activity could reflect a training effect, despite these patients not following any specific training programme before entering the study. Thus, these results would highlight the importance of physical activity as a bridge to obtain a good aerobic capacity, as has been glimpsed in other studies [29].

This study has several strengths. It assesses a single long-term LT patient sample recruited from all over Spain, and the CPET was performed in the same time window and in identical conditions. Likewise, patients underwent not only CEPT but also a comprehensive measurement of other relevant factors such as lean body mass index and completed the IPAQ and EUROQol-5D questionnaires, which allow further analysis of little-known peripheral deficiencies.

The main limitation of this study is the highly selected sample of LT recipients. Long-term survivors after LT with normal spirometry are uncommon. Although it has not been possible to know the exact number of long-term survivors in Spain, in our centre 4\% of all bilateral LT performed survived for 10 years with normal spirometry. Thus, in Spain, from 1124 bilateral LT performed during this period, we estimate that 44 patients would fulfil the criteria to take part in this study (www.ont.es). We think our sample is representative enough, if we take into account that the study required travelling for many patients.

Another related limitation is the high amount of daily activity performed by these patients, which could be related to the preservation of the aerobic capacity, beyond the normal lung function. Despite the fact that the population sample of the current study may not be widely representative, the main outcome was to elucidate whether in the best scenario the LT recipients would be able to achieve normal aerobic capacity. Finally, we do not have information on quadriceps strength, which is a strong correlate of exercise capacity and which would have helped us to describe this population in more detail.

In conclusion, this is, to our knowledge, the first study to describe near-normal $V_{\mathrm{O} 2}^{\prime}$ peak values during CPET and normal aerobic capacity in long-term LT patients. Only age, sex and $D_{\text {LCO }}$ remained significantly associated with $V_{\mathrm{O}_{2}}^{\prime}$ peak $\left(\mathrm{mL} \cdot \mathrm{kg}^{-1} \cdot \mathrm{min}^{-1}\right)$ after adjusting for confounders. The stepwise multiple regression analysis for workload peak revealed anaemia as an independent factor. All the patients included in the study presented a good quality of life and a high exercise capacity.

Acknowledgement: I. Ojanguren is a researcher supported by the "Pla Estratègic de Recerca i Innovació en Salut (PERIS)" 2016-2020 (SLT008/18/00108;G60594009).

Support statement: This study was financed by Instituto de Salud Carlos III (PI13/01076); the European Regional Development Fund (FEDER), FUCAP, Astellas, Novartis and Chiesi. Funding information for this article has been deposited with the Crossref Funder Registry.

Conflict of interest: B. Saez-Gimenez reports lecture fees from GlaxoSmithKline, and travel grants from Actelion Pharmaceuticals, Bial, Mundipharma, Novartis and Astellas Pharma, during the conduct of the study. M. Barrecheguren has nothing to disclose. M.A. Ramon has nothing to disclose. A. Gomez-Garrido has nothing to disclose. C. Bravo has nothing to disclose. V. Monforte has nothing to disclose. M. López-Meseguer has nothing to disclose. C. Berastegui has nothing to disclose. E. Revilla has nothing to disclose. C. Romero has nothing to disclose. R. Laporta has nothing to disclose. S. Fernández-Rozas has nothing to disclose. J. Redel-Montero has nothing to disclose. A. Solé has nothing to disclose. M. de la Torre has nothing to disclose. L. Puente has nothing to disclose. A. Roman has nothing to disclose. S. Gómez-Ollés reports travel grants from Teva and Actelion Pharmaceuticals during the conduct of the study. I. Ojanguren reports personal fees from AstraZeneca, Bial, Boehringer Ingelheim, Chiesi and GlaxoSmithKline, grants and personal fees from Mindipharma, personal fees from Novartis and Teva, grants from Menarini, and personal fees from MSD, during the conduct of the study.

\section{References}

1 Singer JP, Singer LG. Quality of life in lung transplantation. Semin Respir Crit Care Med 2013; 34: 421-430.

2 Levy RD, Ernst P, Levine SM, et al. Exercise performance after lung transplantation. J Heart Lung Transplant 1993; 12: 27-33.

3 Miyoshi S, Trulock EP, Schaefers HJ, et al. Cardiopulmonary exercise testing after single and double lung transplantation. Chest 1990; 97: 1130-1136.

4 Schwaiblmair M, von Scheidt W, Uberfuhr P, et al. Lung function and cardiopulmonary exercise performance after heart transplantation: influence of cardiac allograft vasculopathy. Chest 1999; 116: 332-339.

5 Pellegrino R, Rodarte JR, Frost AE, et al. Breathing by double-lung recipients during exercise: response to expiratory threshold loading. Am J Respir Crit Care Med 1998; 157: 106-110.

6 Williams TJ, Patterson GA, McClean PA, et al. Maximal exercise testing in single and double lung transplant recipients. Am Rev Respir Dis 1992; 145: 101-105. 
7 Bartels MN, Armstrong HF, Gerardo RE, et al. Evaluation of pulmonary function and exercise performance by cardiopulmonary exercise testing before and after lung transplantation. Chest 2011; 140: 1604-1611.

8 Woodson RD, Wills RE, Lenfant C. Effect of acute and established anemia on $\mathrm{O}_{2}$ transport at rest, submaximal and maximal work. J Appl Physiol 1978; 44: 36-43.

9 Craig CL, Marshall AL, Sjöström M, et al. International physical activity questionnaire: 12-country reliability and validity. Med Sci Sports Exerc 2003; 35: 1381-1395.

10 Devlin NJ, Brooks R. EQ-5D and the EuroQol group: past, present and future. Appl Health Econ Health Policy 2017; 15: 127-137.

11 Miller MR. General considerations for lung function testing. Eur Respir J 2005; 26: 153-161.

12 García-Río F, Calle M, Burgos F, et al. Spirometry. Spanish Society of Pulmonology and Thoracic Surgery (SEPAR). Arch Bronconeumol 2013; 49: 388-401.

13 Weisman IM, Weisman IM, Marciniuk D, et al. ATS/ACCP statement on cardiopulmonary exercise testing. Am J Respir Crit Care Med 2003; 167: 211-277.

14 Earthman CP. Body composition tools for assessment of adult malnutrition at the bedside: a tutorial on research considerations and clinical applications. JPEN J Parenter Enteral Nutr 2015; 39: 787-822.

15 Lands LC, Smountas AA, Mesiano G, et al. Maximal exercise capacity and peripheral skeletal muscle function following lung transplantation. J Heart Lung Transplant 1999; 18: 113-120.

16 Ulvestad M, Durheim MT, Kongerud JS, et al. Cardiorespiratory fitness and physical activity following lung transplantation: a national cohort study. Respiration 2020; 99: 316-324.

17 Dudley KA, El-Chemaly S. Cardiopulmonary exercise testing in lung transplantation: a review. Pulm Med 2012; 2012: 237852.

18 Cortes-Telles A, Forkert L, O'Donnell DE, et al. Idiopathic pulmonary fibrosis: new insights on functional characteristics at diagnosis. Can Respir J 2014; 21: e55-e60.

19 Balasubramanian A, MacIntyre NR, Henderson RJ, et al. Diffusing capacity of carbon monoxide in assessment of COPD. Chest 2019; 156: 1111-1119.

20 Gerbase MW, Spiliopoulos A, Rochat T, et al. Health-related quality of life following single or bilateral lung transplantation: a 7-year comparison to functional outcome. Chest 2005; 128: 1371-1378.

21 Künsebeck HW, Kugler C, Fischer S, et al. Quality of life and bronchiolitis obliterans syndrome in patients after lung transplantation. Prog Transplant 2007; 17: 136-141.

22 Finlen Copeland CA, Vock DM, Pieper K, et al. Impact of lung transplantation on recipient quality of life: a serial, prospective, multicenter analysis through the first posttransplant year. Chest 2013; 143: 744-750.

23 Vermuelen KM, van der Bij W, Erasmus ME, et al. Long-term health-related quality of life after lung transplantation: different predictors for different dimensions. J Heart Lung Transplant 2007; 26: 188-193.

24 Kugler C, Fischer S, Gottlieb J, et al. Health-related quality of life in two hundred-eighty lung transplant recipients. J Heart Lung Transplant 2005; 24: 2262-2268.

25 Rutherford RM, Fisher AJ, Hilton C, et al. Functional status and quality of life in patients surviving 10 years after lung transplantation. Am J Transplant 2005; 5: 1099-1104.

26 Cebrià I Iranzo MÀ, Vos R, Verleden GM, et al. Evolution of functional exercise capacity in lung transplant patients with and without bronchiolitis obliterans syndrome: a longitudinal case-control study. Arch Bronconeumol 2019; 55: 239-245.

27 Lanuza DM, Lefaiver CA, Brown R, et al. A longitudinal study of patients'symptoms before and during the first year after lung transplantation. Clin Transplant 2012; 26: E576-E589.

28 Langer D, Burtin C, Schepers L, et al. Exercise training after lung transplantation improves participation in daily activity: a randomized controlled trial. Am J Transplant 2012; 12: 1584-1592.

29 Osho A, Mulvihill $\mathrm{M}$, Lamba $\mathrm{N}$, et al. Is functional independence associated with improved long-term survival after lung transplantation? Ann Thorac Surg 2018; 106: 79-84. 